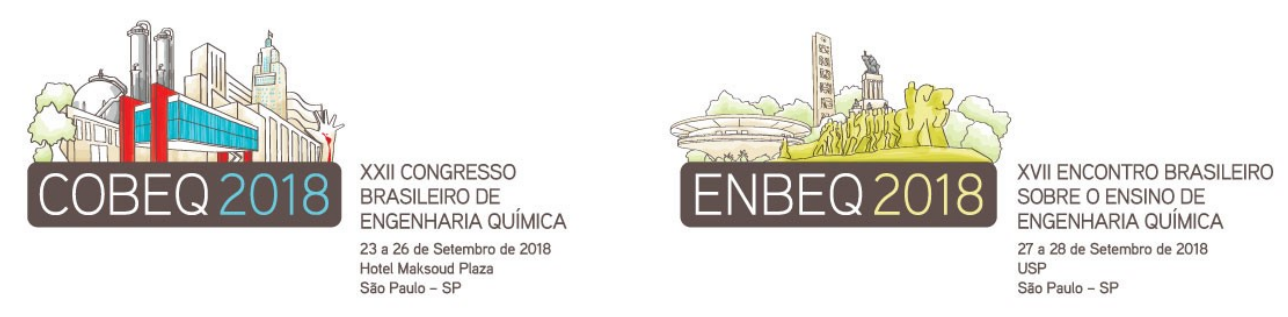

\title{
SACCHAROMYCES CEREVISIAE FED-BATCH FERMENTATION AND ARTIFICIAL INTELLIGENCE METHOD FOR ADJUSTING MODEL PARAMETERS TO EXPERIMENTAL DATA
}

\author{
SOARES MCP ${ }^{1}, \mathrm{LUZ} \mathrm{GF}^{2}$, COSTA AC ${ }^{2}, \mathrm{GOMES} \mathrm{MK}^{1}, \mathrm{MENDES} \mathrm{BF}^{1}, \mathrm{TORRE} \mathrm{LG}^{3}$, \\ FUJIWARA E ${ }^{1}$ \\ ${ }^{1}$ University of Campinas, School of Mechanical Engineering, Laboratory of Photonic Materials and \\ Devices \\ ${ }^{2}$ University of Campinas, School of Chemical Engineering, Department of Products and Processes \\ Development \\ ${ }^{3}$ University of Campinas, School of Chemical Engineering, Department Materials and Bioprocesses \\ Engineering \\ E-mail for contact: marcosoares.feq@gmail.com
}

\begin{abstract}
The fermentation process parameters vary with a range of factors, such as temperature and the composition of the fermentation broth. In order for being used as important project and process monitoring tools, these parameters should be constantly recalculated. In this research, a fermentation model for fed-batch reaction mode is presented, and experimental data are used for showing computation methodologies for recalculating the parameters.
\end{abstract}

\section{INTRODUCTION}

Mathematical models are of immense importance for Chemical Projects, especially when there is a finite amount of experimental data available. In the case of the fermentation, models show a high degree of uncertainty associated with the lack of knowledge about the multiple routes and metabolic pathways of the cells and to the differences between individual cells, commonly treated as homogeneous populations (Bailey and Ollis, 1986; Shuler and Kargi, 2002; Doran, 2013). It is so necessary to compare the predictions to the experimental data, since the parameters of the microbial growth can change for several reasons (Rivera et al., 2007; Andrade et al., 2009): Powchinda and Strehaiano (1999) showed that the reaction rate, in an alcoholic fermentation, is a function of the sugar used as substrate and, if sucrose was used, the rate was inferior than the observed for glucose or fructose. Rivera et al. (2007), in turn, applied two different culture media, one with diluted sugar cane molasses, and other with $\mathrm{MgSO}_{4}$ and yeast extract. Besides varying only a few components, the modifications resulted in a statistically significant differences in model parameters. Other problems regarding the modelling that can be pointed out are: as the composition of the fermentation broth is constantly varying due to the uptake of substrates and to the action of extracellular enzymes produced by the yeast, the effect of the variation of the specific growth rate related to the modification in this composition is able to produce considerable oscillations in reaction rate (Andrade et al., 2009); and there is an increase in the difficult of controlling the broth temperature as the reactor volume rises, producing considerable oscillations of the temperature, which compromise the quality of the models (Andrade et al., 2009). 


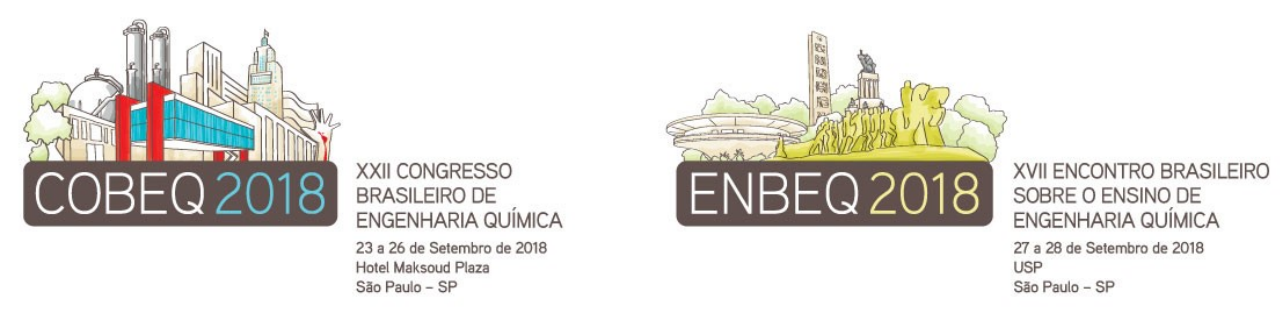

Then, the predictions are only valid for a very strict group of experimental conditions, and a strategy for dealing with this problem is the use of adaptive hybrid models with neural network analysis, which combine the equations from the mass and energy balances with artificial intelligence and use the available experimental data for correcting the process parameters in accordance to the actual environmental conditions (Rivera et al., 2007). It is recommended that the recalculation of the parameters to be performed as a routine procedure (Andrade et al., 2009), and this procedure is not important only for laboratorial operation, but also for the fermentation industries, since they are subject to even more frequent changes in composition of the culture medium and broth composition. Different harvests, for example, can show differences in the chemical composition of the vegetal material used as substrates, as commonly observed for sugarcane molasses (Rivera et al., 2007).

In this research, fermentation experiments with Saccharomyces cerevisiae were conducted in fed-batch reaction mode, using complex media as substrate, and neural network analysis was used for recalculating the parameters previously obtained for Atala et al. (2001).

\section{FERMENTATION MATHEMATICAL MODEL AND FED-BATCH EXPERIMENTS}

The mathematical model applied to this research was the Monod (Equations 1 to 3) with the corrections for the fed-batch model described by Wang and Sheu (2000), Equations 4 to 7.

$$
\begin{aligned}
& \mu=\left(\mu_{m}\right) \frac{s}{K_{M}+S} \\
& q_{p}=Y_{P / X} \mu+m_{p} \\
& \mu_{s}=\frac{1}{Y_{X / S}} \mu+m_{S} \\
& \frac{d V}{d t}=F \Rightarrow V=V_{0}+F t \\
& \frac{d X}{d t}=\mu X-\frac{F}{V} X \\
& \frac{d P}{d t}=q_{p} X-\frac{F}{V} P \\
& \frac{d S}{d t}=-\mu_{S} X+\frac{F}{V}\left(S_{F}-S\right)
\end{aligned}
$$

The culture medium was comprised by a sugarcane syrup with high application in industry previously studied for testing a monitoring methodology based on an optical fiber sensor (Fujiwara et al., 2012). The inoculum growth medium contained 2.30 g. $\mathrm{L}^{-1}$ of urea, 6.6 g.L $\mathrm{L}^{-1}$ of $\mathrm{K}_{2} \mathrm{SO}_{4}, 3.0$ g, $\mathrm{L}^{-1}$ of $\mathrm{KH}_{2} \mathrm{PO}_{4}, 0.5$ g. $\mathrm{L}^{-1}$ of $\mathrm{MgSO}_{4}, 1.0$ g.L $\mathrm{L}^{-1}$ of $\mathrm{CaCl}_{2}, 5.0$ g.L $\mathrm{L}^{-1}$ of yeast extract, $3.0 \mathrm{~g} . \mathrm{L}^{-1}$ of thiamine, $80.0 \mathrm{~g} . \mathrm{L}^{-1}$ of total sugars, and $0.3 \mathrm{mg} . \mathrm{L}^{-1}$ of trace elements. The bioreactor was kept under $33{ }^{\circ} \mathrm{C}, \mathrm{pH} 5.0$, and $100 \mathrm{rpm}$ agitation for 3 hours, with feed flow $\mathrm{F}=0.33333 \mathrm{~L} . \mathrm{h}^{-1}$. The total sugars concentration of the feed current, $\mathrm{S}_{\mathrm{F}}$, and the initial concentration of cells, $\mathrm{X}_{0}$, were different in each experiment, and the bioreactor initial volume of substrate solution was fixed in $\mathrm{V}_{0}=0.5 \mathrm{~L}$. The fermentation model parameters were initially considered equal to the ones obtained by Atala et al. (2001) for the temperature of $33{ }^{\circ} \mathrm{C}: \mu_{\mathrm{m}}=0.4197 \mathrm{~h}^{-1}, \mathrm{~K}_{\mathrm{M}}=4.1 \mathrm{~g} \cdot \mathrm{L}^{-1}, \mathrm{Y}_{\mathrm{P} / \mathrm{X}}=8.7651 \mathrm{~g} . \mathrm{g}^{-1}, \mathrm{Y}_{\mathrm{X} / \mathrm{S}}=0.0539$ 


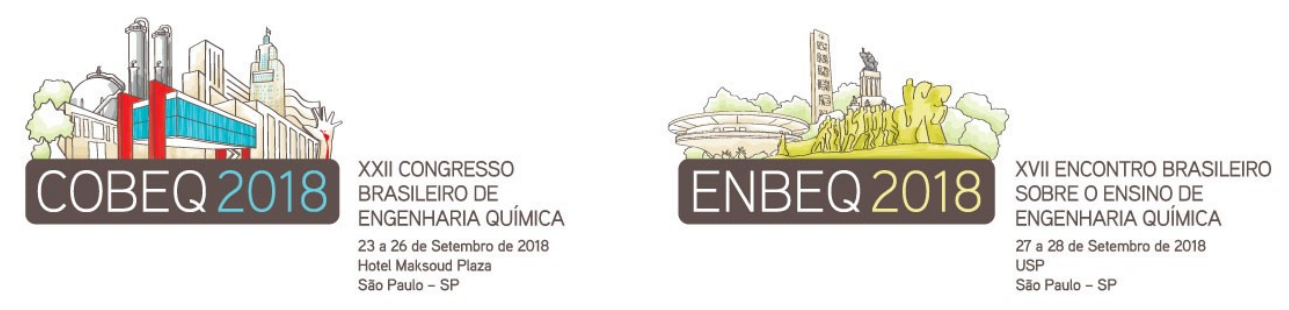

g. $\mathrm{g}^{-1}, \mathrm{~m}_{\mathrm{p}}=0.1 \mathrm{~h}^{-1}$, and $\mathrm{m}_{\mathrm{s}}=0.2 \mathrm{~h}^{-1}$. After the experiments, the yeast mass, $\mathrm{X} . \mathrm{V}$, was evaluated with the dry-mass method, and the HPLC analysis of the fermentation broth was performed, revealing the presence of xylose, cellobiose, ethanol, acetic acid and glycerol. The experiments did not indicate the inhibition of fermentation by the presence of the major product, ethanol, and showed a consistent difference for the parameters obtained by Atala et al. (2001). It was expected, since the culture media used were different and due to the fact that, in fed-batch mode, a stream of substrate is continuously added to the bioreactor, so the cells need to adapt their metabolism to the shear stresses associated to the flow (Bailey and Ollis, 1986; Shuler and Kargi, 2002; Doran, 2013).

Finally, an artificial neural network (ANN) process was used for determining the process parameters, and only the coefficient $K_{M}$ was kept constant and equals to the value obtained by Atala et al. (2001), since it was verified that it had small effect on the quality of the adjusted model. The network consisted in a backpropagation architecture, in which the $\mathrm{S}, \mathrm{X}$, and $\mathrm{P}$ values are used as the input, and the ANN returns the values of $\mu_{\mathrm{m}}, \mathrm{Y}_{\mathrm{P} / \mathrm{X}}, \mathrm{Y}_{\mathrm{X} / \mathrm{s}}, \mathrm{m}_{\mathrm{p}}$, and $\mathrm{m}_{\mathrm{s}}$. The number of network layers was defined as 2 , once the training time in this situation was considerably lower than the required for the networks with more layers, the number of synapses were determined as 100 for the intermediate layer, and 5 for the output layer, and the activation functions were defined as hyperbolic and sigmoid tangent, respectively. Initially, the network was trained in accordance to the normalized values obtained in simulation for each one of 4 fed-batch experiments data set, and the training function used was the gradient descent with momentum. As the values calculated for the different experiments were considerably close, the new parameters were defined as the mean values of the ANN output data: $\mu_{\mathrm{m}}=0.186 \mathrm{~h}^{-1}, \mathrm{Y}_{\mathrm{P} / \mathrm{X}}=2.660 \mathrm{~g} \cdot \mathrm{g}^{-1}, \mathrm{Y}_{\mathrm{X} / \mathrm{S}}=0.188 \mathrm{~g} \cdot \mathrm{g}^{-1}, \mathrm{~m}_{\mathrm{p}}=0.010 \mathrm{~h}^{-1}$, and $\mathrm{m}_{\mathrm{s}}=$ $0.290 \mathrm{~h}^{-1}$. In order to verify the performance of the training, the results of the model predictions were compared to the data obtained for a fifth experiment, and it was considered that the model predictions were in accordance to the experimental data, showing deviations lower than $20 \%$. This process for obtaining the model parameters with the ANN is summarized in Figure 1 and the results obtained for the five experiments, compared to the model predictions, are shown in Figure 2.

\section{CONCLUSIONS}

Besides being a powerful tool for equipment and manufacturing projects, the fermentation kinetic models treat as constants parameters that should be continuously recalculated, since they depend on a series of external factors.

The models can show different degrees of complexity, according to the operation mode used and to the experimental data available. In this work, it was showed how computational neural network tools can be used for allowing a professional the process of modelling and recalculating parameters for the fed-batch mode in accordance to the experimental data, obtaining results that fits satisfactorily well the experiments, with errors not greater than $20 \%$.

Despite the importance for the calculus of mass balances, for the prediction of the fermentation production, it is important to emphasize that the results are reproducible, but the parameters obtained should be only applied with confidence for the particular environmental conditions of the research, being considered as initial approximations for other studies. 

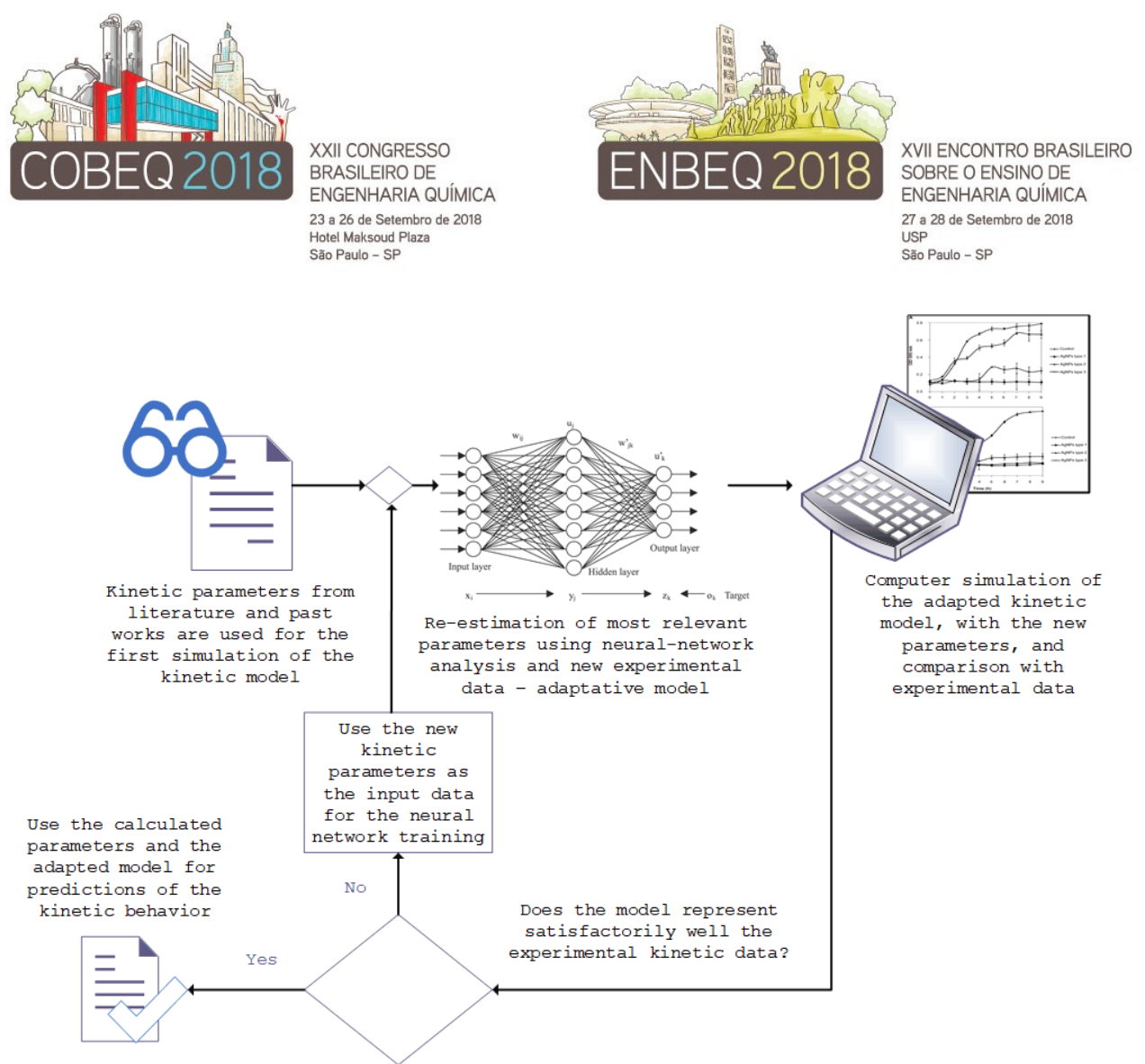

Figure 1 - Process of recalculating the kinetic parameters of the fermentation process with neural network analysis.
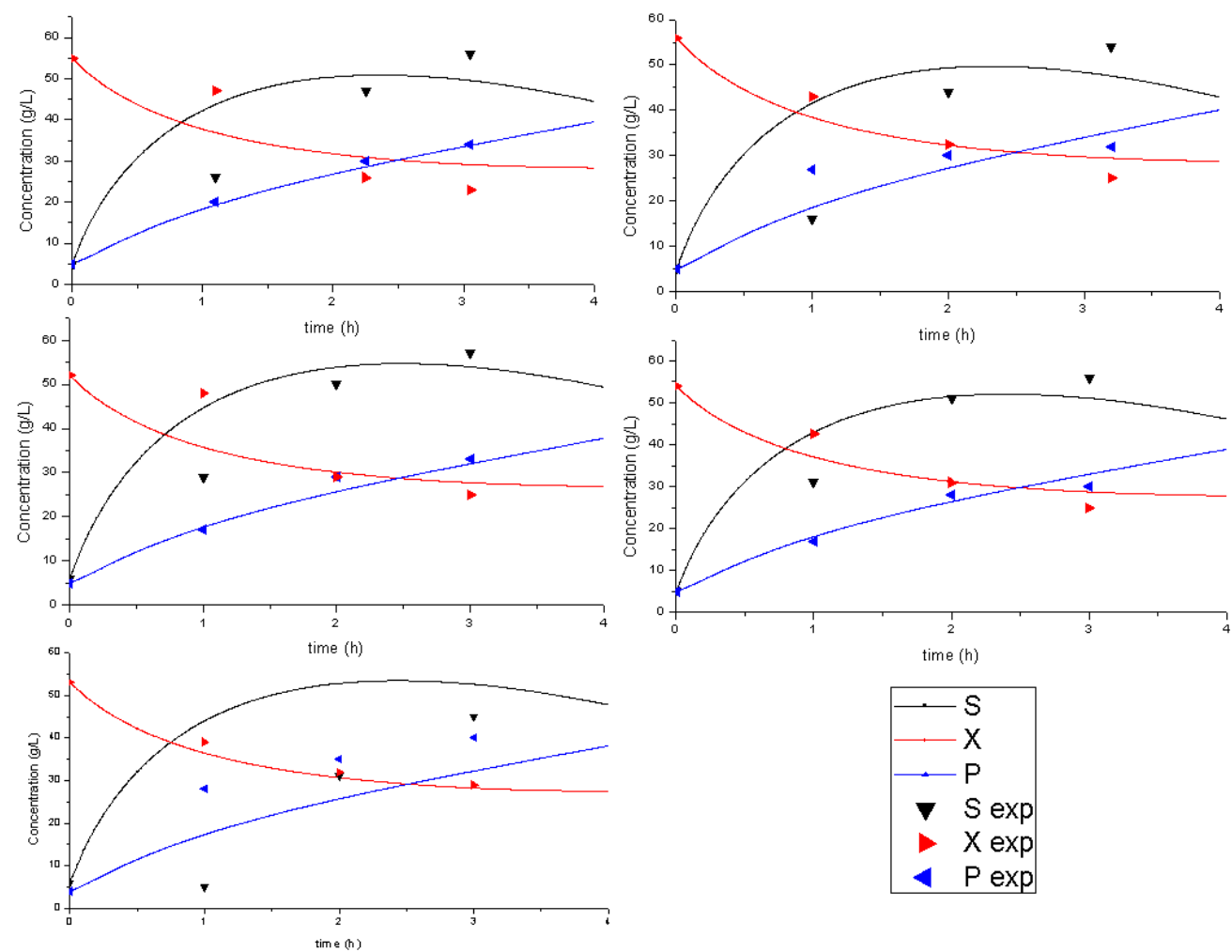

Figure 2 - Experimental data obtained, and fermentation profiles calculated with the model with the recalculated parameters (concentration in g. $\mathrm{L}^{-1}$ vs. time in $\mathrm{h}$ ). The experiments are represented by the points and the subscript "exp", whereas the model is represented by continuous lines. S, X and $\mathrm{P}$ indicates the concentration profiles of substrate, cell biomass, and products, respectively. 

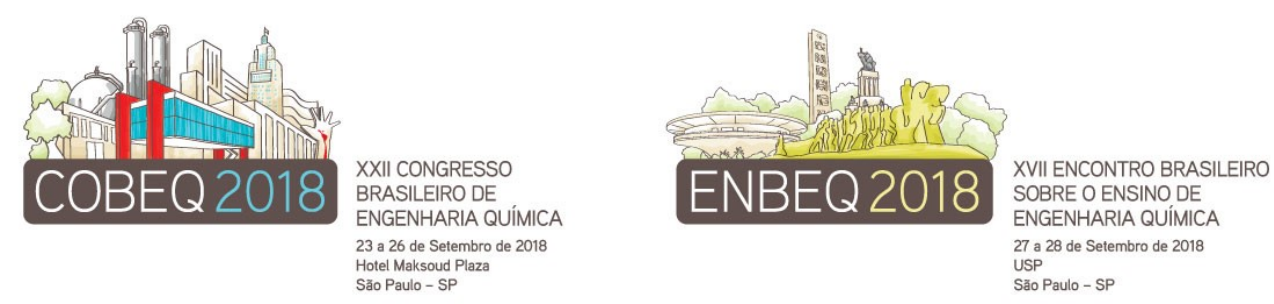

\section{ACKNOWLEDGMENTS}

This work was supported in part by Sao Paulo Research Foundation (FAPESP) under grants 2017/06190-7 and 2017/20445-8, CNPq and CAPES.

\section{REFERENCES}

ANDRADE RR, RIVERA EC, ATALA DIP, MACIEL FILHO R, MAUGIERI FILHO F, COSTA AC. Study of kinetic parameters in a mechanistic model for bioethanol production through a screening technique and optimization. Bioprocess Biosyst. Eng., v.32, p. 673-680, 2009.

ATALA DIP, COSTA AC, MACIEL FILHO R, MAUGERI FILHO F. Kinetics of ethanol fermentation with high biomass concentration considering the effect of temperature. Appl. Biochem. Biotechnol., v.91-93, p. 353-364, 2001.

BAILEY J, OLLIS D. Biochemical Engineering Fundamentals. Second Edition. McGraw-Hill, 1986.

DORAN P. Bioprocess Engineering Principles. Second Edition. Elsevier, 2013.

FUJIWARA E, ONO E, IAMAKAWA CK, IENCZAK JL, ROSSELL CEV, SUZUKI CK. Realtime monitoring of fermentation process applied to sugarcane bioethanol production. OFS-22, Beijing, China, 2012.

POWCHINDA O, STREHAIANO P. Utilization of Mixed Sugars for Alcoholic Fermentation by Saccharomyces cerevisiae. Thammasat Int. J. Sci. Tech., v.4, p. 23-31, 1999.

RIVERA EC, COSTA AC, ANDRADE RR, ATALA DIP, MAUGIERI FILHO F, MACIEL FILHO R. Development of adaptive modeling techniques to describe the temperature-dependent kinetics of biotechnological processes. Biochem. Eng. J., v.36, p. 157-166, 2007.

SHULER M, KARGI F. Bioprocess Engineering. Basic Concepts. Second Edition. Prentice Hall, 2002.

WANG F-S, SHEU, J-W. Multiobjective parameter estimation problems of fermentation processes using a high ethanol tolerance yeast. Chem. Eng. Sci, v.55, p. 3685-3695, 2000. 